\title{
REPORTS
}

\section{Clay Flake Orientation in a Sensitive Pleistocene Clay*}

NEAL R. O'BRIEN

Department of Geology, State University of New York, Potsdam

WILLIAM HARRISON

Department of Civil Engineering, Clarkson College of Technology

Potsdam, New York

\section{Introduction}

The purpose of this paper is to report preliminary findings of an electron microscope investigation of clay flake orientation in a sensitive Pleistocene marine clay. Very little information has been published concerning the actual observed fabric of sensitive clay, therefore, it was felt that an electron microscope study might shed additional light upon the reasons for sensitivity. ROSENQVIST (1959) published electron micrographs of Norwegian quick clays. The photographs presented in this paper are believed to be the first showing details of the fabric of a sensitive clay found in the St. Lawrence River Valley.

The clay investigated is found at water level approximately 600 feet downstream from Snell Lock on the St. Lawrence River, near Massena, New York. At this location the clay is 4.0 feet thick and lies directly on Ordovician bedrock. However, upstream and downstream from Snell Lock, the clay overlies two distinctive tills which range from 6 to 55 feet in thickness (U.S. ARMY ENG. REPT. 1958). MacCLINTOCK (1958) has identified the lower till as the Malone till of the Cary substage of Wisconsin glaciation and the upper till as Fort Covington of the Valders substage.

Undisturbed cores were obtained by inserting Shelby tubing into the saturated clay on the river bottom. Cores were slowly air dried in the laboratory and after drying were extracted and broken open. Carbon replicas were then made of the surface of the clay. Because of the roughness of the fresh surface, specimens were rotated during shadowing, shadow angle being approximately $90^{\circ}$. Replicated specimens were placed into hydrofluoric acid, dissolving the clay and allowing the carbon replica to float free. After remaining in the acid bath for two days, the replicas were washed in distilled water and mounted on 200 mesh copper grids.

\section{Clay Properties and Fabric}

GOLDSCHMIDT (1926), CASAGRANDE (1932), LAMBE (1953), TAN (1957), and ROSENQVIST (1959) have presented theories which support a honeycomb or cardhouse arrangement of clay flakes in sensitive soils. KERR (1963) showed, diagrammatically, the orientation of clay and silt grains in a quick clay in both the undisturbed and remoulded states. Electron micrographs of the Oslo Blue clay published by ROSENQVIST $(1959,1960)$ show this sensitive clay to be composed of randomly oriented clay flakes. Rosenquist concluded that the mineral arrangement in the undisturbed clay corresponds to the card-house structure suggested by Goldschmidt, Lambe, and Tan.

The soil index properties of the clay examined are similar to those reported for other sensitive clays:

*Manuscript received 5 December, 1966 

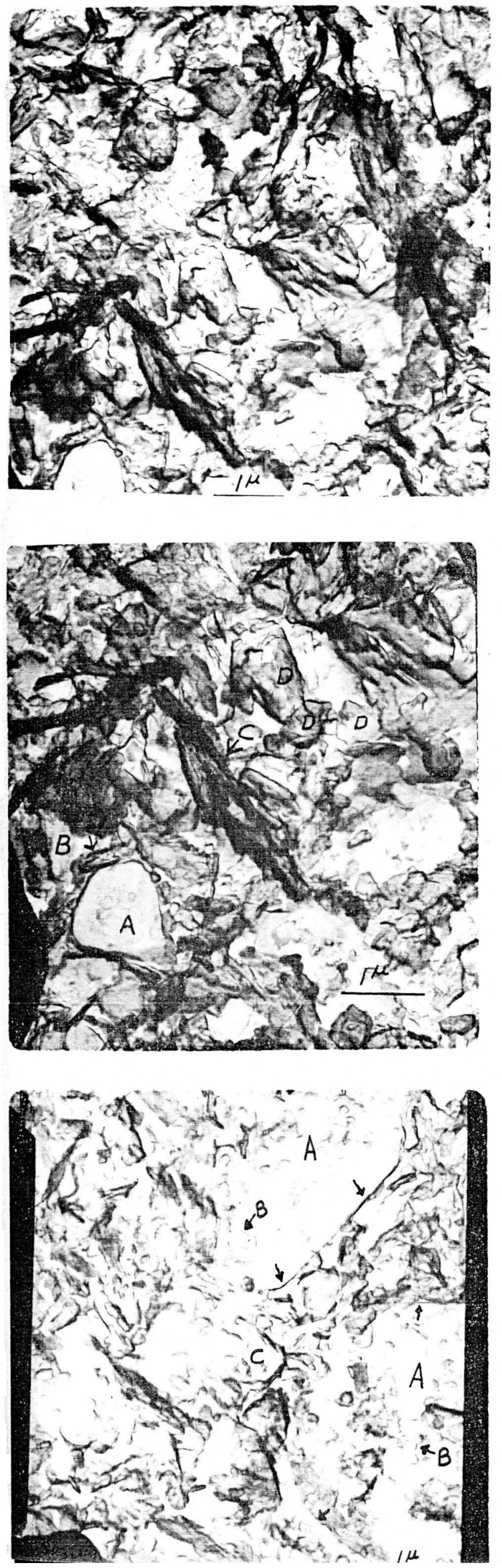

\section{Figure 1}

Electron Micrograph of Pleistocene clay. Magnification 11, 660x, carbon replica. Clay flakes are tilted at various angles.

\section{Figure 2}

Electron Micrograph of a Pleistocene clay, enlargement of a section of Figure 1. Magnification 14,000x, carbon replica. A is a silt grain, $B$ points to clay flakes coating a silt grain and perpendicular to the plane of the photo, $C$ show $s$ an area of a collapsed floccule lying perpendicular to the photo, and $D$ indicates flat lying clay flakes.

\section{Figure 3}

Electron Micrograph of a Pleistocene clay. Magnification 11,660x, carbon replica. Two large silt grains are marked by point $A$, grain borders indicated by arrows. B marks individual clay flakes coating grains and $C$ shows randomly orientated flakes in the clay matrix. 


$\begin{array}{lc}\text { Liquid Limit }(\%) & 4.8 \\ \text { Plastic Limit }(\%) & 25 \\ \text { Mositure content (\% dry weigltt) } & 62 \\ \text { Specific gravity } & 2.80 \\ \text { Sensitivity } & 20 \\ \text { Salt content }(g / 1 .) & 0.4 \\ \text { Particle size }(\%<5 \mu) & 67\end{array}$

Electron micrographs of the illitic Pleistocene clay show a fabric similar to the clays studied by Rosenquist. The most apparent feature is the random orientation of clay flakes (Figure 1). Silt grains appear to be floating in a clay matrix composed of a jumbled mass of clay platelets. X-ray analysis of the clay flake orientation according to a technique discussed by O'BRIEN (1964) corroborates the random orientation observed in electron micrographs. Figure 2 is an enlargement of a portion of Figure 1 and shows in detail the mutual relationship of silt grains and clay. Particular attention is called to a group of flakes at point $C$ in Figure 2. The authors interpret this as a collapsed clay aggregate or floccule. Many such structures were observed in other electron micrographs not included in this report. The gross fabric tends to suggest deposition of the clay in the flocculated state as compared to the dispersed state.

The relationship of clay flakes to large silt grains is displayed in Figure 3. Individual clay flakes appear to coat the silt'grains (see flakes at points B on grains A). However, the silt grains themselves are separated by randomly oriented clay aggregates ( $\mathrm{C}$ in Figure 3).

The electron micrographs offer additional evidence of the random orientation of clay flakes in sensitive clay. This orientation may have been produced by deposition of the clay in the flocculated state. LIEBLING and KERR (1965, p. 868) state "...... random stacking of clay particles has been attributed to coagulating effects of electrolytes. " Marine fossils have been reported in the clay at the sample location, (personal communication, F.J.E. WAGNER, Bedford Institute of Oceanography), thus supporting the belief that the clay was deposited in a saline or electrolyte-rich environment. Regardless of mode of origin the electron micrographs do indicate a random clay flake orientation, which possibly contributed to sensitivity of the Pleistocene clay. Further work is being conducted by the authors in investigating changes in fabric during remoulding.

The authors are grateful to the Research Foundation of the State University of New York and the Division of Research, Clarkson College of Technology for their financial support.

\section{References cited}

CASAGRANDE, A., 1932, The structure of clay and its importance in foundation engineering: Boston Society of Civil Engineers, Journal, vol. 19, p. 168-209.

GOLDSCHMIDT, V.M. , 1926, Unders $\phi k$ kelser over lersedimenter: Nordisk jordbrugsforskning, no. 4-7, p. 434-445.

KERR, P.F., 1963, Quick clay: Scientific American, vol. 209, no. 5, pp. 132-142.

LAMBE, T.W., 1953, The structure of inorganic soils: American Society of Civil Engineers, proceedings, vol. 79, separate, $315,49 \mathrm{p}$.

LIEBLI NG, R.S. and KERR, P.F., 1965, Observations on quick clay: Geological 
Society of America Bulletin. vol. 76, p. 853-878.

MacCLINTOCK, P., 1958, Glacial geology of the St. Lawrence Seaway and Power Projects: New York State Museum and Science Service, Albany, 26 p.

O'BRIEN, N.R., 1964, Origin of Pennsylvanian underclays in the Illinois Basin: Geological Society of America Bulletin, vol. 75, p. 823-832.

ROSENQVIST, I. Th, 1959, Physico-chemical properties of soils: soil-water systems: Soil Mechanics and Foundations Division, American Society of Civil Engineers, vol. 85, no. SM2, p. 31 - 53,

, 1960, The influence of physio-chemical factors upon the mechanical properties of clays: Clays and Clay Minerals, Proceedings of the Ninth National Conference on Clays and Clay Minerals, vol. 9, p. 12-27.

TAN, T.K., 1957, Discussion:- International Conference on Soil Mechanic and Foundation Engineering, no. 4, proceedings, vol. 3, p. 87.

U. S. ARMY CORPS OF ENGINEERS, 1958, Foundation Report - Bertrand H. Snell Lock, St. Lawrence Seaway, International Rapids Section: U. S. Army Engineer District, Buffalo, ed. Victor O. Wilson, 89 p. 